\title{
FPGA Based Implementation of Cascaded Multi-level Inverter with Adjustable DC Sources
}

\author{
Author(s): ${ }^{* 1}$ Hatef Firouzkouhi \\ Affiliation(s): ${ }^{1}$ Atmospheric Science Department \\ University of Nevada, Reno, NV, United States of America \\ *Corresponding Author: h.f.kouhi@gmail.com
}

\begin{abstract}
In this paper, total harmonic distortion (THD) minimization problem for cascaded $\mathrm{H}$ Bridge multilevel inverters (CHB-MLIs) with unequal DC sources is studied, which the DC voltage levels of CHB-MLI is considered to be dependent on switching angles. Two forms of variations are proposed for DC voltage, considering corresponding switching angles. A simplified THD formulation, independent from the DC voltage is presented. Both Homotopy method and Genetic Algorithm is applied for THD minimization using Selective Harmonic Elimination PWM (SHEPWM). The results show less THD results using GA. The simulation results are demonstrated by experiments on a seven-level inverter controlled by Xilinx SPARTAN3 FPGA (XC3S400-PQG208). The results show that switching angles for minimum THD can be considered constant for desired fundamental voltages.
\end{abstract}

Keywords: Cascaded multilevel inverter, Genetic Algorithm (GA), Total Harmonic Distortion (THD), Homotopy method, Selective Harmonic Elimination PWM (SHEPWM).

\section{INTRODUCTION}

The increasing concerns regarding energy demands and pollution levels have opened the door for exploring renewable energy resources [1]. In this regard, power inverters are widely used to convert the variable DC output of renewable resources into a utility AC frequency and help the voltage and frequency stabilizations in power systems. Multilevel inverters are widely applied in industrial applications like high-voltage direct current (HVDC), electrical drives, and flexible ac transmission system (FACTS) devices [2], [3]. Cascaded multilevel inverter seems to be an attractive configuration due to its simplicity and its modularity which consists of several cells or $\mathrm{H}$ - bridge inverters connected in series in order to achieve highvoltage levels and reduced THD.

Several well-known switching strategies are used in cascaded H-Bridge multilevel inverters (CHB-MLIs) topology. These switching strategies are pulse width modulation (PWM) [4],[5] sinusoidal pulse width modulation (SPWM) [6], space vector pulse width modulation (SVPWM) [7], [8] and selective harmonic elimination PWM (SHEPWM) [9], [10]. In these methods, switching angles, DC voltages or both are determined to minimize the voltage THD [11]. A fundamental issue in the control of an effective multilevel inverter is to reduce THD [11]. In SHEPWM strategy low-order harmonics are eliminated. This strategy requires a solving method for the nonlinear equations. Nonlinear equations always refer to harmonic contents, which are to be omitted or minimized. Some of these methods include iterative methods such as the Newton-Raphson, Homotopy method [6] or iterativeanalytical methods [12]. Optimization algorithms are also widely used in solving the nonlinear problems [13], [14], [15], [16], [17].

An innovative approach of using constraint satisfaction problem techniques to solve nonlinear optimization problems which doesn't trap in local minima of the optimization problem is presented in [18]. Moreover, some of them such as NSGAII [19], MOFWA [20], MOPSO [21], PaCcET [22], SFS [23] can also solve multi-objective optimizations for various problems. In [23], an effective multi-objective approach to the SFS algorithm called NRSFS is presented which is successfully applied to handle the nonlinear constraints. NR-SFS algorithm is used in [24] to find the optimum switching angles and DC voltages in cascaded multi-level inverter.

In [6], DC voltages are proposed to be independent from any level of fundamental voltage and proportional to corresponding switching angles. In CHB-MLI applications such as electrical drives and VAR compensators it is 
necessary to have a flexible output voltage. In other words, output voltage has to be continuously supplied according to system's instantaneous requirements. So, fundamental voltage has to be controllable at the desired range. In this paper, it has been tried to find the optimum form of the relevance between DC sources and switching angles which leads to minimum value of THD. So, two different forms of relation between switching angles and DC voltages is examined. Genetic Algorithm (GA) is used as SHEPWM solving method to find the optimum relation which leads to minimum THD. As a comparison to GA, Homotopy method is applied for solving SHEPWM nonlinear equations. Finally, the results obtained from GA and Homotopy method are compared and the best relation is introduced.

\section{CASCADED MULTI-LEVEL INVERTERS}

The H-bridge topology called cell, with four switches is used to synthesize a three-level square-wave output voltage waveform. This characteristic of the CHB-MLI allows approaching the sinusoidal waveform with small harmonic contents. In [11], a comprehensive study on a CHB-MLI based STATCOM shows that the harmonics and losses of the distribution system can be reduced successfully. Fig. 1 (a) shows the configuration of cascaded multilevel inverter. Because of the series connection of the cells the overall output voltage of multilevel inverter is given by:

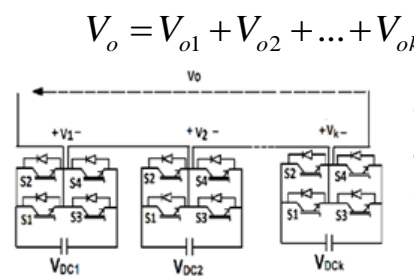

(a)

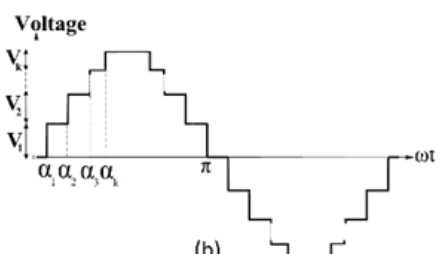

Fig. 1: (a): The schematic, (b): typical stair case output voltage of CHB-MLI

Proper switching of $S 1$ to $S 4$ in each cell output generates $+V_{D C},-V_{D C}$, and zero at the output. A typical cycle waveform with switching angles and voltage levels is shown in Fig. 1(b).

The Switching angles of the other quarters of this symmetrical waveform can be found easily. Fourier Transform is used as a powerful tool for frequency analyzing and measuring the signals [25]. The Fourier series of the waveform in Fig. 1(b) is given in the following:

$$
V(\omega t)=\sum_{n=1,3,5, \ldots}^{\infty} V_{n} \sin (n \omega t)
$$

Where $V_{n}$ is the amplitude of voltage harmonics and is given by:

$$
V_{n}= \begin{cases}\frac{4}{n \pi} \sum_{k} V_{D C k} \cos \left(n \alpha_{k}\right) & \text { For odd } n \\ 0 & \text { For even } n\end{cases}
$$

where $k$ is the number of $\mathrm{H}$-bridge cells and $V_{D C k}$ is the voltage of the $\mathrm{k}^{\text {th }}$ DC source. It is obvious that even harmonic orders do not exist in symmetric waveforms.

\section{THD CALCULATION}

In this section, the conventional method to calculate the THD of voltage is introduced. The general waveform is shown in Fig. 2. The THD of this waveform is computed by:

$$
T H D=\frac{\sqrt{\sum_{n=3}^{\infty} V_{n}^{2}}}{V_{1}}
$$

Where $V_{n}$ is the amplitude of harmonic components and is computed by (3)

Since, triple harmonics are eliminated in the line voltage, (4) is rewritten as:

$$
T H D=\frac{\sqrt{\sum_{n=5,7,11, \ldots}^{\infty} V_{n}^{2}}}{V_{1}}
$$

However, taking all harmonics into account is a big problem. Thus, low-order harmonics until a specified harmonic are considered so that an approximate answer is yielded. In this paper THD is calculated until $31^{\text {th }}$ order.

\section{PROPOSED ESTIMATION FUNCTION}

Likewise [6], in this paper, switching angles are proposed to be independent from the output fundamental voltage. Therefore, once obtained, they will be used for any output voltage. In this paper two forms of $\operatorname{Cos}^{P}($.$) and 1-\operatorname{Sin}^{P}($. with a variable parameter $P$ are proposed as the relation between DC source voltage and its corresponding switching angle.

\section{A. $\operatorname{Cos}^{P}$ form of estimation function $\left(E_{1}\right)$}

In this case, the DC voltage sources are set as (6):

$V_{D C k}=C V_{1} \cos ^{P}\left(\alpha_{k}\right)$

Where the following constraints is satisfied for switching angles and DC voltages:

$$
\begin{aligned}
& \alpha_{1}<\alpha_{2}<\ldots<\alpha_{k}<\frac{\pi}{2} \\
& V_{D C 1}, V_{D C 2}, \ldots, V_{D C k}<1
\end{aligned}
$$


By substituting (6) in (3) for $n=1$, we will have $V_{1}=\frac{4}{\pi} \sum_{k} C V_{1} \cos ^{P}\left(\alpha_{k}\right) * \cos \left(\alpha_{k}\right) \cdot C$ is a constant which is found as (9).

$$
C=\frac{\pi}{4} \frac{1}{\sum_{k} \cos ^{P+1}\left(\alpha_{k}\right)}
$$

By substituting $C$ in the (3), nth voltage harmonic is obtained as follows:

$$
V_{n}=\frac{4}{n \pi} \sum_{k} C V_{1} \cos ^{P}\left(\alpha_{k}\right) \cos \left(n \alpha_{k}\right)
$$

By substituting (10) in (5), THD is calculated by (11):

$$
T H D=\frac{4 C}{\pi} \sqrt{\sum_{n=5,7,11, . .}^{31}\left(\sum_{i=1}^{k} \frac{\cos \left(n \alpha_{k}\right) \cos ^{P}\left(\alpha_{k}\right)}{n}\right)^{2}}
$$

Harmonic elimination equations are written as (12) in order to eliminate $5^{\text {th }}, 7^{\text {th }}$ and $11^{\text {th }}$ order harmonics.

$\cos ^{P}\left(\alpha_{1}\right) \cos \left(n \alpha_{1}\right)+\cos ^{P}\left(\alpha_{2}\right) \cos \left(n \alpha_{2}\right)+\cos ^{P}\left(\alpha_{3}\right) \cos \left(n \alpha_{3}\right)=0$

For $\mathrm{n}=5,7,11$

In this paper, (11) is the objective function to be minimized and (12) is the constraint.

\section{B. 1-sin ${ }^{P}$ form of estimation function $\left(E_{2}\right)$}

In this section, (13) is considered as the second form of estimation $\left(\mathrm{E}_{2}\right)$. With the same reasoning, the following equations for $\mathrm{C}, V_{n}$ and THD would be obtained:

$V_{D C k}=C V_{1}\left(1-\sin ^{P}\left(\alpha_{k}\right)\right)$

by substituting (13) in (3) for $n=1$, we will have $V_{1}=\frac{4}{\pi} \sum_{k} C V_{1}\left(1-\sin ^{P}\left(\alpha_{k}\right)\right) * \cos \left(\alpha_{k}\right) \cdot C$ is a constant which is found as (14).

$C=\frac{\pi}{4} \frac{1}{\sum_{k}\left(1-\sin ^{P}\left(\alpha_{k}\right)\right) \cos \left(\alpha_{k}\right)}$

By substituting $C$ in the (3), nth voltage harmonic is obtained as follows:

$V_{n}=\frac{4}{n \pi} \sum_{k} C V_{1}\left(1-\sin ^{P}\left(\alpha_{k}\right)\right) \cos \left(n \alpha_{k}\right)$
By substituting (15) in (5), THD is calculated by (16):

$T H D=\frac{4 C}{\pi} \sqrt{\sum_{n=5,7,11, \ldots}^{31}\left(\sum_{i=1}^{k} \frac{\cos \left(n \alpha_{k}\right)\left(1-\sin ^{P}\left(\alpha_{k}\right)\right)}{n}\right)^{2}}$

$\left(1-\sin ^{P}\left(\alpha_{1}\right)\right) \cos \left(n \alpha_{1}\right)+\left(1-\sin ^{P}\left(\alpha_{2}\right)\right) \cos \left(n \alpha_{2}\right)+\left(1-\sin ^{P}\left(\alpha_{3}\right)\right) \cos \left(n \alpha_{3}\right)=0$,

For $\mathrm{n}=5,7,11$

Substituting (17) into harmonics elimination equations of SHEPWM, it results in a set of equations that the switching angles as solutions to the problem. Then, the obtained switching angles are placed into THD formula, according to (16).

\section{OPTIMIZATION RESULTS}

GA is a stochastic global search tool which has been widely used in solving complicated optimization problems [24], [26], [27],[28]. As a heuristic optimization method, it does not require any derivative information. In this paper, GA is used to define the optimal switching angles and DC voltage sources for SHEPWM technique. It is also used to define switching angles and $\mathrm{P}$ to minimize the THD for proposed estimation functions. For each optimization problem, 100 trial and error runs are performed using MATLAB. Moreover, Homotopy method is used for solving SHEPWM nonlinear equations for both estimation functions. Nonlinear equations always refer to low order harmonic contents, which are to be eliminated. Some of these methods include iterative methods such as the Newton-Raphson, Homotopy method [6] or iterative-analytical methods [12]. Homotopy belongs to continuation methods and represents a way to find a solution to a problem by constructing a new problem, simpler than the original one, and then gradually deforming this simpler problem into the original one keeping track of the series of zeros that connect the solution of the simpler problem to that of the original, harder one.

\section{A. SHEPWM using GA}

In this case, two minimizations are performed applying MATLAB. A minimization is done to minimize (11) as the objective function and another to minimize (16). Constraint function are also (12) and (17) respectively. Optimum switching angles and $P$ which lead to the minimum THD are determined. Optimization results tabulated in Tables. I-II.

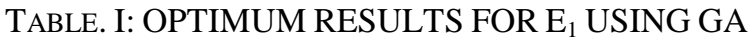

\begin{tabular}{|c|c|c|c|c|}
\hline THD\% & $\boldsymbol{\alpha}_{\mathbf{1}}$ & $\boldsymbol{\alpha}_{\mathbf{2}}$ & $\boldsymbol{\alpha}_{3}$ & $\mathbf{P}$ \\
\hline 3.587 & 5.17 & 15.57 & 34.79 & -0.14 \\
\hline
\end{tabular}


TABLE. II: OPTIMUM RESULTS FOR E E $_{2}$ USING GA

\begin{tabular}{|c|c|c|c|c|}
\hline THD\% & $\boldsymbol{\alpha}_{\mathbf{1}}$ & $\boldsymbol{\alpha}_{\mathbf{2}}$ & $\boldsymbol{\alpha}_{\mathbf{3}}$ & $\mathbf{P}$ \\
\hline 3.587 & 5.17 & 15.57 & 34.79 & -0.14 \\
\hline
\end{tabular}

The minimum THD for this case was obtained equal to $3.587 \%$. So, $\operatorname{Cos}^{-0.14}($.) is the estimation function which leads to minimum THD.

\section{B. SHEPWM using Homotopy method}

In this case, SHEPWM technique is applied. For this, harmonic elimination equations based on constraints are solved, so that $5^{\text {th }}, 7^{\text {th }}$ and $11^{\text {th }}$ order harmonics are eliminated. The Newton Homotopy method is employed to solve mentioned equations. Different values of $\mathrm{P}$ are placed in to these equations. Switching angles which are the roots of equation are obtained. Then, THD for these angles is calculated according to (11). The above mentioned steps are also repeated for (17) and THD values are obtained according to (16). The obtained switching angles versus $P$, for $E_{1}$ and $E_{2}$ using Homotopy method are plotted in Figs.34 respectively. Also, obtained THDs are shown in Figs. 5-6.

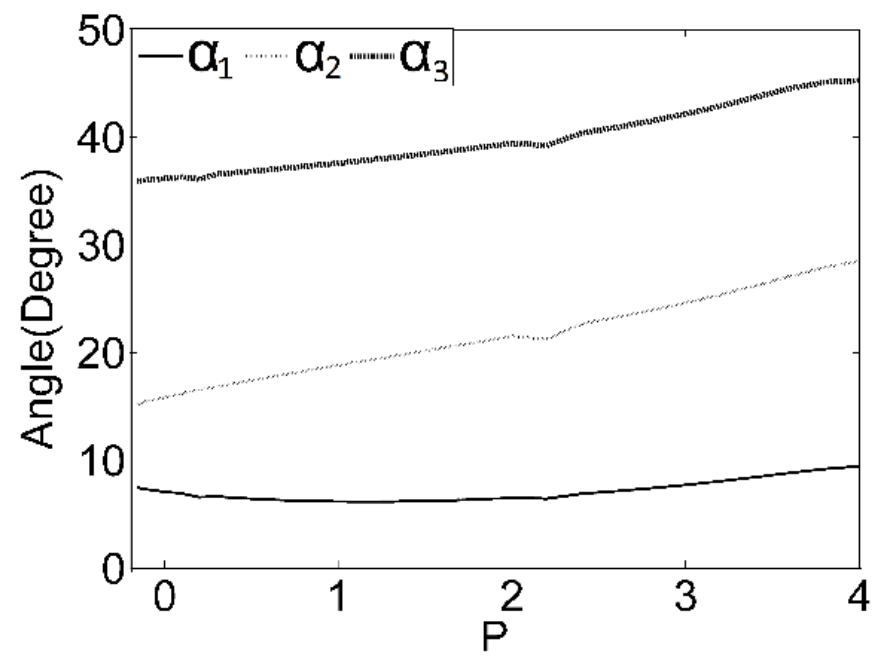

Fig. 2: Switching angles vs. $\mathrm{P}$ for $\mathrm{E}_{1}$ by Homotopy

TABLE III: OPTIMUM RESULTS FOR $\mathrm{E}_{1}$ USING HOMOTOPY METHOD

\begin{tabular}{|c|c|c|c|c|}
\hline THD\% & $\boldsymbol{\alpha}_{\mathbf{1}}$ & $\boldsymbol{\alpha}_{\mathbf{2}}$ & $\boldsymbol{\alpha}_{\mathbf{3}}$ & $\mathbf{P}$ \\
\hline 4.571 & 6.97 & 16.1 & 36.27 & -0.07 \\
\hline
\end{tabular}

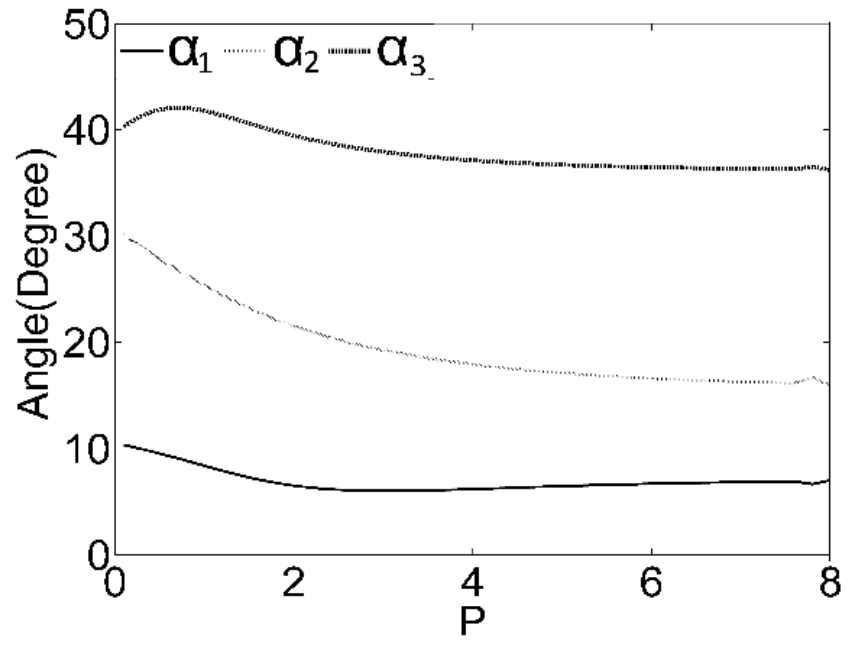

Fig. 3: Switching angles vs. $\mathrm{P}$ for $\mathrm{E}_{2}$ by Homotopy

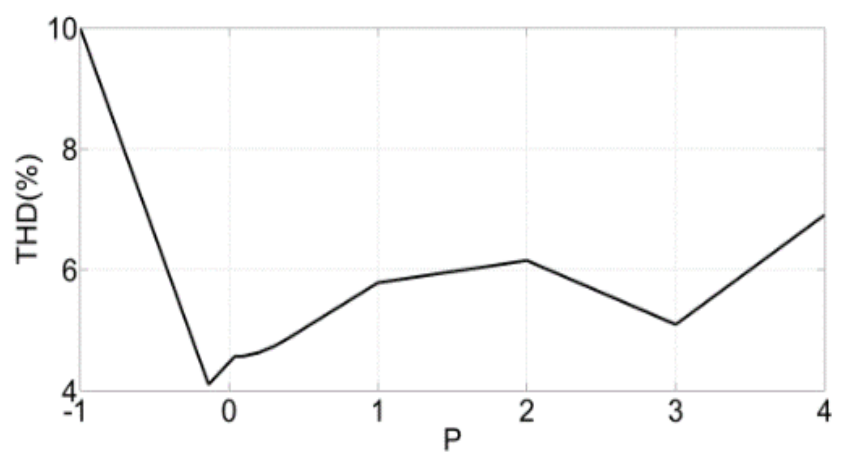

Fig. 4: THD vs. $\mathrm{P}$ for $\mathrm{E}_{1}$ by Homotopy

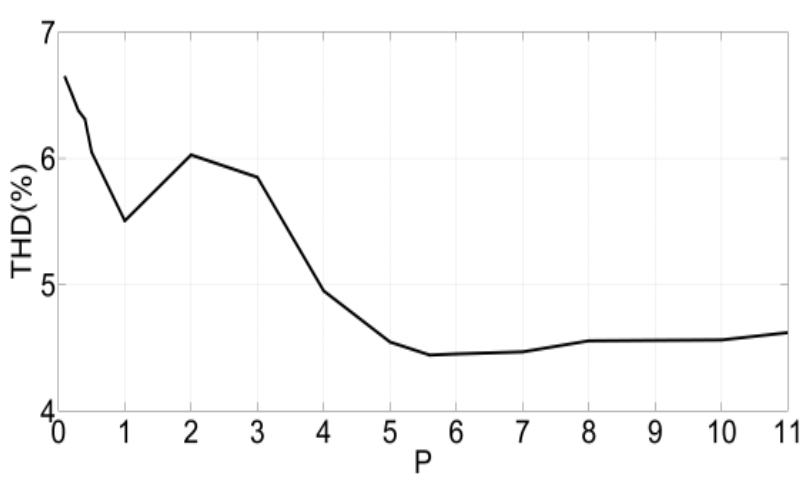

Fig. 5: THD vs. $\mathrm{P}$ for $\mathrm{E}_{2}$ by Homotopy

TABLE IV: OPTIMUM RESULTS FOR E $E_{2}$ USING HOMOTOPY METHOD

\begin{tabular}{|c|c|c|c|c|}
\hline THD\% & $\boldsymbol{\alpha}_{1}$ & $\boldsymbol{\alpha}_{2}$ & $\boldsymbol{\alpha}_{3}$ & P \\
\hline 4.449 & 6.74 & 16.53 & 36.45 & 6.2 \\
\hline
\end{tabular}

The minimum THD for this case was obtained equal to $4.571 \%$. So, $\operatorname{Cos}^{-0.074}($.) is the estimation function which leads to minimum THD. By comparing Table I-IV, it can be observed that using both methods, the $\mathrm{E}_{1}$ is the better form 
of estimation which gives the minimum THD. On the other hand, the results of Table I give the least THD. Thus, it can be inferred that the GA performance in SHEPWM method dominates Homotopy method in this case.

\section{EXPERIMENTAL RESULTS}

Fig. 6 shows experimental prototype of a single phase multilevel inverter. It consists of five $\mathrm{H}$-bridges which are connected in a series form. The number of $\mathrm{H}$-bridges can be removed by proper switching patterns. Switching angles are obtained offline according to Tables I-IV. Owing to requirements of high accuracy in implementation of switching angles, a Xilinx SPARTAN3 FPGA (XC3S400PQG208) is applied in this paper. More explained details of the experimental set up can be found in [24]. Figs. 7-10 show the experimental waveforms for the results of Tables I-IV.

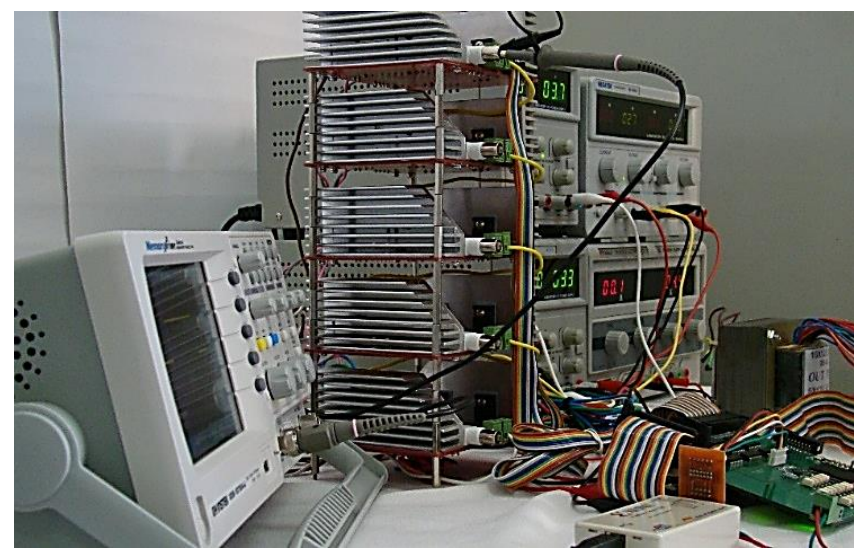

Fig. 6: Experimental Test System

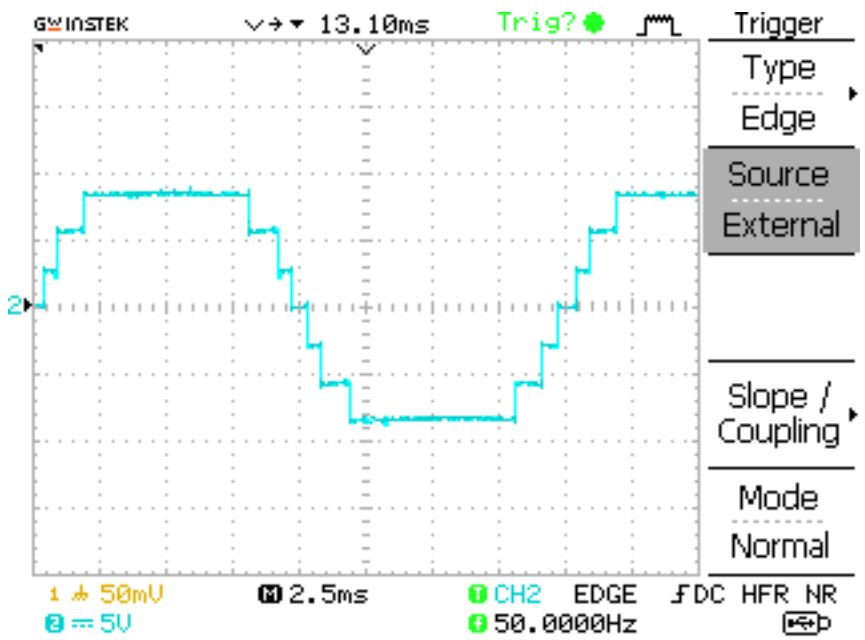

Fig. 7: Experimental waveform for the results of Table I

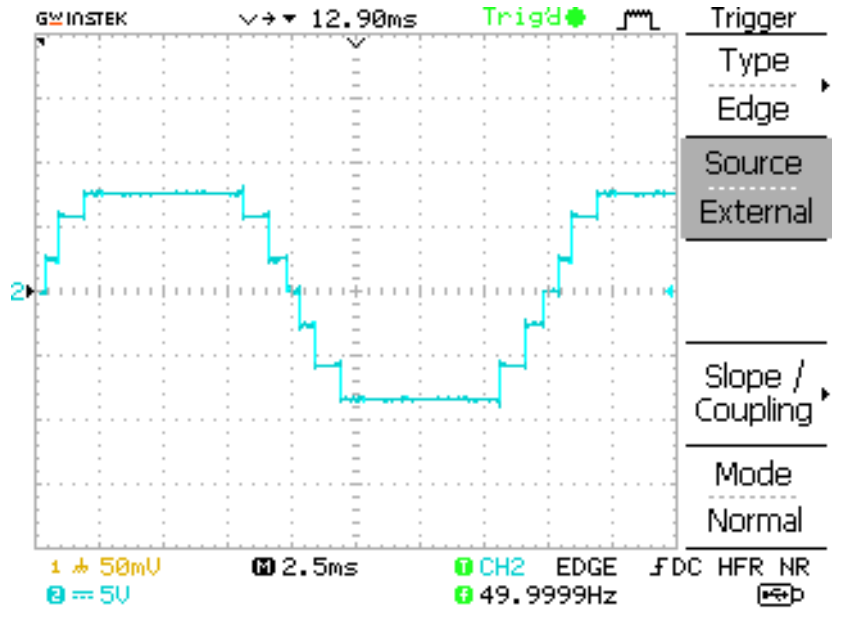

Fig. 8: Experimental waveform for the results of Table II

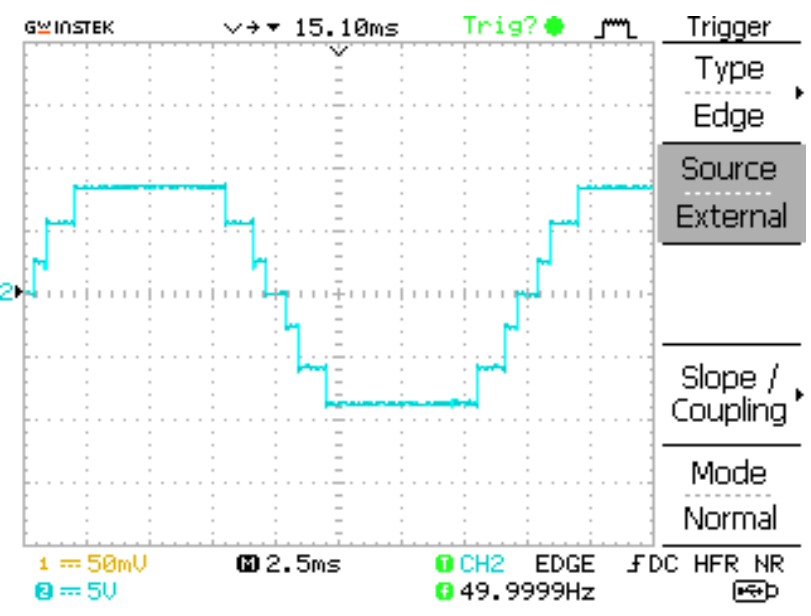

Fig. 9: Experimental waveform for the results of Table III

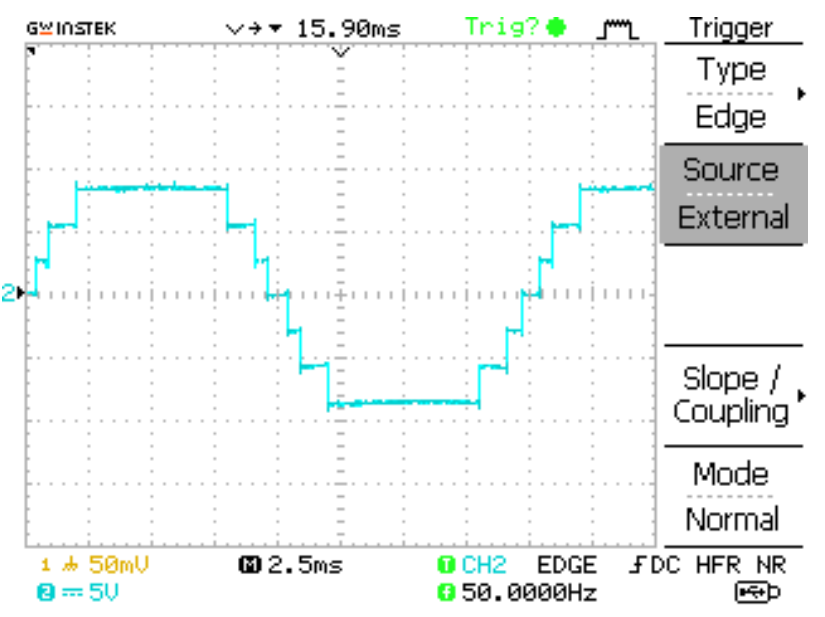

Fig. 10: Experimental waveform for the results of Table IV

\section{CONCLUSION}

A new concept in THD minimization for cascaded multilevel inverter with unequal DC sources has been proposed in this paper. According to this concept, unequal DC voltage levels and switching angles could be selected to make output voltage as close as to the desired fundamental value with minimum THD. Therefore, switching angles are 
calculated only once. In order to acquire minimum THD, a proper form for DC voltage levels relative to corresponding switching angle is found using SHEPWM. The SHEPWM have been applied to both GA and Homotopy method. The simulation results for both methods verify that Optimum results show switching angles for minimum THD are always constant for any desired fundamental voltage. Thus, to have flexible output voltage for applications such as electric machine drives, the minimum THD can be obtained, while output voltage is controlled at the desired value. Future research on output voltage control of inverter interface renewable energies can also be a worthy effort.

\section{DECLARATION}

Author has disclosed no conflicts of interest.

\section{REFERENCE}

[1] M. Parvizimosaed, A. Anvari-Moghaddam, A. Ghasemkhani and A. Rahimi-Kian, "Multi-objective dispatch of distributed generations in a gridconnected micro-grid considering demand response actions," 22nd International Conference and Exhibition on Electricity Distribution (CIRED 2013), Stockholm, 2013, pp. 1-4.

[2] O. A. Gashteroodkhani, B. Vahidi, and A. Zaboli, "Time-time matrix $\mathrm{z}$-score vector-based fault analysis method for series-compensated transmission lines," Turkish Journal of Electrical Engineering \& Computer Sciences, vol. 25, pp. 2647-2659, 2017.

[3] M. A. Chitsazan, G. Gharehpetian, M. Arbabzadeh, "Application of voltage source convector in interphase power controller", Proc. of World Congress on Engineering and Computer Science (WCECS), vol. 2, pp. 1-6, Oct. 2012.

[4] A. Aghazadeh, I. Niazazari, N. Khodabakhshi, S. H. Hosseinian, and H. A. Abyaneh, "A new method of single-phase active power filter for AC electric railway system based on Hilbert transform," in IEEE International Conference on Smart Energy Grid Engineering, SEGE 2013, 2013.

[5] P. Palanivel and S. S. Dash, "Analysis of THD and output voltage performance for cascaded multilevel inverter using carrier pulse width modulation techniques," IET Power Electron., vol. 4, no. 8, p. 951, 2011.

[6] S. H. Fathi, M. G. Hosseini Aghdam, A. Zahedi, and G. B. Gharehpetian. "Optimum regulation of DC sources in cascaded multi-level inverters." COMPEL-The international journal for computation and mathematics in electrical and electronic engineering 28, no. 2 (2009): 385-395.
[7] M. Valan Rajkumar and P. S. Manoharan, "FPGA based multilevel cascaded inverters with SVPWM algorithm for photovoltaic system," Sol. Energy, vol. 87, no. 1, pp. 229-245, 2013.

[8] D. M. Lee, J. W. Jung, and S. S. Kwak, "Simple space vector PWM scheme for 3-level NPC inverters including the overmodulation region," $J$. Power Electron., vol. 11, no. 5, pp. 688-696, 2011.

[9] M. Srndovic, A. Zhetessov, T. Alizadeh, Y. L. Familiant, G. Grandi, and A. Ruderman, "Simultaneous Selective Harmonic Elimination and THD Minimization for a Single-Phase Multilevel Inverter with Staircase Modulation," IEEE Trans. Ind. Appl., vol. 54, no. 2, pp. 1532-1541, 2018.

[10] T. Sudhakar Babu, K. Priya, D. Maheswaran, K. Sathish Kumar, and N. Rajasekar, "Selective voltage harmonic elimination in PWM inverter using bacterial foraging algorithm," Swarm Evol. Comput., vol. 20, pp. 74-81, 2015.

[11] S. M. R. Tousi and S. Aznavi, "Performance optimization of a STATCOM based on cascaded multi-level converter topology using multi-objective Genetic Algorithm," in Electrical Engineering (ICEE), 2015 23rd Iranian Conference on, 2015, pp. 1688-1693.

[12] A. Forooghi Nematollahi, A. Dadkhah, O. Asgari Gashteroodkhani, and B. Vahidi, "Optimal sizing and siting of DGs for loss reduction using an iterative-analytical method," Journal of Renewable and Sustainable Energy, vol. 8, no. 5, p. 055301, 2016.

[13] M. Jafari, V. Sarfi, A. Ghasemkhani, H. Livani, L. Yang, H. Xu, and R. Koosha, "Adaptive neural network based intelligent secondary control for microgrids," in Texas Power and Energy Conference (TPEC), 2018 IEEE. IEEE, 2018, pp. 16.

[14] Kazemi, Seyed Farzan, and Yousef Shafahi. "An Integrated Model Of Parallel Processing And PSO Algorithm For Solving Optimum Highway Alignment Problem." In ECMS, pp. 551-557. 2013.

[15] M. A. Chitsazan and A. M. Trzynadlowski, "Harmonic mitigation in interphase power controller using passive filter-based phase shifting transformer," in ECCE 2016 - IEEE Energy Conversion Congress and Exposition, Proceedings, 2016.

[16] Khayyam Nekouei, Rasoul, Amir Peyman Soleymani, Saeed Akhavan, Ali Ashrafi NasrAbadi, and Alireza Aghababaei Samani. "Using Taguchi Method to Optimize Recovery of Bismuth by Electrolysis." Physical Chemistry \& Electrochemistry 3, no. 1 (2015): 39-48.

[17] A. Zolfaghari, M. Goharimanesh, and A. A. Akbari, "Optimum design of straight bevel gears pair using evolutionary algorithms," J. Brazilian Soc. Mech. 
Sci. Eng., vol. 39, no. 6, pp. 2121-2129, 2017.

[18] H. Khodabandehlou and M. S. Fadali, "A quotient gradient method to train artificial neural networks," Neural Networks (IJCNN), 2017 International Joint Conference on, pp. 2576-2581, 2017.

[19] K. Deb, A. Pratap, S. Agarwal, and T. Meyarivan, "A fast and elitist multiobjective genetic algorithm: NSGA-II," IEEE Trans. Evol. Comput., vol. 6, no. 2, pp. 182-197, 2002.

[20] V. Sarfi, I. Niazazari, and H. Livani, "Multiobjective fireworks optimization framework for economic emission dispatch in microgrids," in NAPS 2016 - 48th North American Power Symposium, Proceedings, 2016.

[21] B. Zhao and Y. Cao, "Multiple objective particle swarm optimization technique for economic load dispatch," J. Zhejiang Univ. Sci., vol. 6A, no. 5, pp. 420-427, 2005.

[22] V. Sarfi, H. Livani, "A New Multi-Objective Economic-Emission Dispatch in Microgrids", 2017 IEEE PES General Meeting, Chicago, Illinois, USA, July $16 \sim 20,2017$.

[23] S. Aznavi, P. Fajri, M. Benidris and B. Falahati, "Hierarchical droop controlled frequency optimization and energy management of a gridconnected microgrid," in 2017 IEEE Conference on Technologies for Sustainability (SusTech), Phoenix, AZ, USA, 2017, pp. 1-7.

[24] H. Firouzkouhi, " Application of Flexible OMTHD Technique to Cascaded Multi-level Inverter and the FPGA Based Implementation of Control System", International Research Journal of Engineering and Technology (IRJET), Vol. 05, Issue. 05, pp.19161922, May-2018.

[25] M. Rahimi, Y. Luo, F. C. Harris, S. M. Dascalu and Y. Shen, "Improving measurement accuracy of Position Sensitive Detector (PSD) for a new scanning PSD microscopy system," 2014 IEEE International Conference on Robotics and Biomimetics (ROBIO 2014), Bali, 2014, pp. 16851690.

[26] A. G. Kaviri, M. N. M. Jaafar, and T. M. Lazim, "Modeling and multi-objective exergy based optimization of a combined cycle power plant using a genetic algorithm," Energy Convers. Manag., vol. 58, pp. 94-103, 2012.

[27] Niazazari, I., Vahidi, B., \&Abyaneh, H. A. (2013), Loss reduction of wind turbine with optimization of blade length using genetic algorithm. Science International, 25(4), pp. 807-811.

[28] P. Hoseini, A. Khoei, K. Hadidi and S. Moshfe, "Fast and flexible genetic algorithm processor," 2011 18th IEEE International Conference on Electronics, Circuits, and Systems, Beirut, 2011, pp. 635-638. 